\title{
Do Project Management Tools and Outcomes Differ in Organizations of Varying Size and Sector?
}

\author{
Kimberly Furumo \\ University of Hawaii, Hilo, \\ HI, USA \\ furumo@hawaii.edu
}

\author{
J. Michael Pearson \\ Southern Illinois University, \\ Carbondale, IL, USA \\ jpearson@cba.siu.edu
}

\author{
Nancy L. Martin \\ Southern IIlinois University, Carbondale, IL, USA \\ nImartin@siu.edu
}

\begin{abstract}
While studies of information systems (IS) project management are plentiful, few studies have investigated how the tools and techniques used in project management differ for varying types of organizations. In this study we surveyed members of the Project Management Institute who work as IS project managers in a variety of different organizations both public and private and large and small. Results show that the practices and tools utilized in varying organizations are largely similar even though the literature suggests that these organizations face different challenges. However, projects completed in governmental organizations in the public sector come in behindschedule more often than those completed in organizations in the private sector. These findings provide insights for project managers in a variety of organizational settings.
\end{abstract}

Keywords: IS project management, small organizations, public sector, government organizations.

\section{Introduction}

As information technology improves and the cost of technology becomes more affordable, organizations that once found it prohibitive to include innovative information systems technologies in their business models no longer find this to be the case. The term information systems (IS) project is used to describe a wide variety of different projects which, when completed, help the organization update or expand its information technology infrastructure. These projects focus on implementing or updating the organization's hardware and software and include software applica-

Material published as part of this journal, either on-line or in print, is copyrighted by the Informing Science Institute. Permission to make digital or paper copy of part or all of these works for personal or classroom use is granted without fee provided that the copies are not made or distributed for profit or commercial advantage AND that copies 1) bear this notice in full and 2) give the full citation on the first page. It is permissible to abstract these works so long as credit is given. To copy in all other cases or to republish or to post on a server or to redistribute to lists requires specific permission and payment of a fee. Contact Publisher@InformingScience.org to request redistribution permission. tion development projects, e-commerce applications, network upgrades, and data management and data warehousing applications to name a few. IS project teams complete tasks such as identifying hardware and software requirements, estimating costs, and coordinating the installation of various hardware and software applications. These tasks can be outsourced to a company that specializes in IS project management or han- 
dled in-house. In-house project teams may include technical staff, functional users and outside consultants. The coordination of these IS projects is referred to as IS project management. IS project management can be defined as the use of tools, techniques and methods to coordinate an IS project team, within a given set of constraints.

Project management, as it relates to information systems, is not a new concept. During World War II, the need for project management became obvious because the government needed a way to systematically track the numerous projects that were occurring simultaneously (Frame, 1994). In the 1960s, IS project management became associated with complex mainframe systems (Brooks, 1987). As we enter the $21^{\text {st }}$ century, the computing environment is more dynamic and global than ever (Collins \& Kirsch, 1999; Wetherbe, Vitalari, \& Millner, 1994). Given the complex, dynamic, and global environment in which many organizations operate, understanding the factors which influence the success or failure of IS project management is paramount.

Studies suggest that a significant percentage of IS projects run into problems, many requiring additional resources to complete. Problems may be related to poor planning and goal setting (Guinan, Cooprider, \& Faraj, 1998; Yetton, Martin, Sharma, \& Johnston, 2000), team leadership (Hartman \& Ashrafi, 2002; Zmud, 1980), or lack of support from upper management (Aladwani, 2002). The Standish Group International Inc. (2001), a research advisory firm, surveyed executives and found that American companies spent an estimated \$22 billion in IS project overruns and $\$ 75$ billion on software projects that were eventually cancelled.

While project management in IS is not a new area of study, previous research has not distinguished how project management practices vary in different types of organizations. This study focuses on two criteria in which organizations vary. First, organizations may vary by sector. Some organizations are in the public sector, while others are in the private sector. Private sector organizations may be publicly traded or privately owned. Organizations in the public sector are government organizations that are technically owned by taxpayers or publicly owned.

Second, organizations vary by size. The Small Business Administration www.sba.gov/size/ defines small businesses according to sales $(\$)$ and number of employees. In general, but not in all cases, organizations with 500 or fewer employees are considered small businesses. In the business related literature, researchers refer to small and medium business enterprises (SMEs). There does not seem to be a specific definition for SMEs, however, most authors view them as profitmaking businesses of limited size, which stand alone and not as a subsidiary of a company, and have regular accounting practices and produce financial statements. The size of the enterprise varies by country with smaller, less developed countries setting the size limit at 200 employees and smaller, and more developed countries setting the size limit at 500 or fewer employees.

The following sections of this paper include a review of the research related to project management and different organizational types, the development of hypotheses which guide this study, and the results of a survey of project managers.

\section{Literature Review and Hypothesis Development}

\section{IS Project Management Practices}

IS project management has been studied from many different perspectives. Practitioners have studied project management tools and job functions (Frame, 2003; Heldman, 2003; Schwalbe, 2004; Taylor, 2004) that lead to successful management of projects while academics have studied the impact of various socio-psychological factors on project management (Barki \& Hartwick, 2001; Beath, 1987; Birkhead, Sutherland, \& Maxwell, 2000; Foster, 2001; Keil \& Robey, 1999; Kirsch, 1997; Yetton et al., 2000). 
Previous research has established a positive relationship between formal project management practices and project performance (Aladwani, 2002; Deephouse, Mukhopadhyay, Goldenson, \& Kellner, 1995; Guinanet al., 1998; Sukhoo, Barnard, Eloff \& Van der Poll, 2005b). Research suggests that most IS project problems are related to management of organizational and cultural issues, rather than technical problems (Hartman \& Ashrafi, 2002; Zmud, 1980). These findings imply that project management is a critical component of IS project success.

Formal project management practices include setting goals, creating plans and providing documented rules, standards and procedures to the project team. Research has repeatedly established a relationship between formal project management practices and project performance. Project planning was consistently associated with favorable project outcomes in terms of schedule and budget (Deephouse et al., 1995). The need for effective plans and procedures as well as the setting of clear goals and milestones were also found to be critical to project success (Guinan et al., 1998). A direct link between planning and budget performance (Yetton et al., 2000) and other project outcomes (Aladwani, 2002) in IS projects has also been established. Other research has noted that project goals impact project planning and the control process (Abdel-Hamid, 1999).

The combination of hard and soft skills were summarized in a study completed by the Northwest Center for Emerging Technology (1999) with the assistance of a grant from the National Science Foundation. Included were the following:

- Define scope of the project

- Identify stakeholders, decision makers, and escalation procedures

- Develop detailed task list (work breakdown structures)

- Estimate time requirements

- Develop initial project management flow chart

- Identify required resources and budget

- Prepare contingency plans

- Identify interdependencies

- Identify and track critical milestones

- Participate in project phase review

- Secure needed resources

- Manage the change control process

- Report project status

Schwalbe (2004) noted the importance of project management integration including project scope management, project time management, project cost management, project quality management, project human resources management, project communications management, project risk management and project procurement management.

Until the 1980s, project management tools, such as work breakdown structures and Gantt charts, were used primarily to provide schedule and resource data to upper management (Schwalbe, 2004). However, with improvements in automated project management software, many organizations have found these project management tools to be effective in managing projects. Many organizations claim that use of project management tools and techniques allows for better control of financial and human resources, improved customer service, shorter development times, lower costs, higher quality and increased reliability, higher profit margins, improved productivity, better internal control, and higher worker morale (Schwalbe, 2004) .

Taylor (2004) suggested that the four most important tools for project managers are the work breakdown structure (WBS), network analysis, the Gantt chart, and earned value reporting. A WBS provides a structured view of the various components of a project, organized in successively lower tiers of detail. A good WBS allows a project manager to develop every other tool 
needed to successfully manage the project. The WBS should be used as the basis for planning, scheduling, budgeting, and controlling the project.

Network analysis has been used since the 1950s when Lockheed and Booz Allen Hamilton developed PERT (project evaluation and review technique) for the Navy. PERT involves developing an estimated duration and labor requirements for each task. Interdependencies in tasks are identified so that tasks that can be completed at the same time are identified. Boxes and arrows are used to diagram the total project task by task, including any interdependencies in task, and then a critical path is identified.

The Gantt chart was developed by Henry Gantt in 1917. A Gantt chart is a bar chart which displays planned and actual progress of a project against projected time lines. Gantt charts can be easily created in most project management software systems and therefore provide sophisticated views of how a project is progressing. In theses systems, a projected baseline is set and activity completion is compared with the baseline.

Finally, earned value reporting, often called earned value management (EVM), is a technique used to track the accomplishment of a project and variances between planned and actual costs and time schedules. This tool allows the project manager to integrate scope, time, and cost data. Data from EVM are used to develop charts that help the project manager and senior management visualize how the project team is performing.

\section{Public and Private Sector Organizations}

Despite the numerous studies related to factors which influence IS project management, few have addressed the impact of organization type on IS project performance. During the 1990s, researchers began to distinguish between management information systems (MIS) designed for public (government) and private sector organizations (Bretschneider, 1990; Cats-Baril \& Thompson, 1995; Caudle, 1990; Newcomer \& Caudle, 1991). Bretschneider (1990) studied public management information systems (PMIS) and suggested that they varied from MIS systems in private enterprises. He identified several differences in managing information systems between the public and private sectors. First, Bretschneider suggested there was a much greater level of interdependence across organizational boundaries in the public sector as he points out in the following passage:

"The authority of the public organization derives in part from legal and constitutional arrangements. Embedded in those institutions are traditional concerns for checks and balances, often manifested as oversight groups or external organizational control of personnel activity and financial resources. Consequently, public organizations exhibit greater interdependence across organizational boundaries than do private organizations." (Bretschneider, 1990, p.537)

This greater interdependence leads to greater oversight which leads to more procedural steps and delays. Bretschneider (1990) describes this phenomenon as the higher level of "red tape" experienced by public sector organizations.

A second difference between public and private sector organizations relates to management activities. Bretschnieder (1990) suggested that managers in private sector organizations are more concerned with internal coordination while public sector managers are concerned with linkages outside the organization. Therefore, the focus in establishing and maintaining private MIS is the bottom line or the cost-benefit analysis while in public MIS other criteria (i.e. procedural equity) compete with the bottom line.

A third difference is the location of the MIS chief in the organizational chart. In private sector organizations, the MIS chief is at the highest level of the organization. Conversely, the MIS chief 
Furumo, Pearson, \& Martin

in the public sector organization is normally placed at a lower level to buffer the IS function from the turbulence caused by frequent political changes leading to discontinuities of leadership. (Bretschneider, 1990).

Newcomer and Caudle (1991) suggest that another distinction of public sector information systems is the variety of users of the system. Users are more likely to be both internal and external to the organization. For instance, the legislature may need information about a public function and request an ad hoc report from a public organization.

To summarize, information systems developers are likely to face additional obstacles when working in public sector organizations. The greater level of oversight present in public sector organizations requires increased coordination and additional levels of approval. Because of the increased number of constituents or customers, it is more costly and takes longer to complete projects. Thus, the following hypotheses were developed.

H1: Projects in public sector organizations are more likely to go over-budget than projects in private sector organizations.

$\mathrm{H} 2$ : Projects in public sector organizations are more likely to be delivered late than projects in private sector organizations.

Public sector organizations face high levels of scrutiny from a number of different constituency groups including voters, regulatory agencies, and other governmental bodies. To develop effective information systems, that deliver information in a variety of different formats for the multiple constituencies, it is necessary to gather input from more end users in public sector organizations than in private sector corporations and small businesses. In addition, the political nature of public sector organizations leads to increased employee turnover at all ranks. To insure the continuation and completion of large IS projects, sharing knowledge about the project is important. If the project team is composed of numerous constituents, it is likely that these teams are more physically dispersed.

H3: IS project team members are more likely to be dispersed geographically in public sector organizations than in private sector organizations.

IS project teams, working in public sector organizations, may face a more complex environment. In addition to the multiple levels of bureaucracy, increased oversight, and the dynamics of the political environment, team members may be more dispersed. To be successful in this complex environment, communication and coordination between the project team, management, and the end users is crucial. For this reason, the following hypothesis is developed.

H4: IS project teams in public sector organizations are more likely to use standardized tools and procedures such as the WBS, network analysis, Gantt charts, and Earned Value Reports than teams in private sector organizations.

\section{Size of the Organization}

Research related to how IS project management and performance differs for organizations of varying sizes is limited. Some studies have focused on information systems/information technology (IS/IT) adoption (Caldeira \& Ward, 2002; Knol \& Stroeken, 2001). Within this framework, many researchers noted the difficulty SMEs face in developing IS capabilities (Calderia \& Ward, 2002; Knol \& Stroeken, 2001; Stroeken, 2001). Billi and Raymond (1993) suggest that SMEs have fewer financial resources, lower technical expertise, and poorer management skills when comparing them to larger organizations. Employees are often asked to wear many hats. The lack of specialization may lead to limited technical expertise which is likely to have an impact on project outcomes. Thus the following hypothesis can be developed. 
H5: Projects in small organizations ( $\leq 500$ employees) are more likely to be delivered late than projects in large organizations.

However, because smaller organizations have fewer resources, staff are likely to be more aware of the need to manage resources closely. Costs may be harder to hide. Project managers are likely to be aware of the fact that their project could be cancelled or deferred if funds are expended for non-planned expenses. For this reason, managers may be more likely to manage budgets closely and identify cost variances as they occur. Therefore, the following hypothesis is developed.

H6: Projects in small organizations are less likely to come in over-budget than projects in large organizations.

Since small organizations have fewer employees, they may be more likely than large organizations to have staff located in a single physical location. In this case, the project team may be located in a single location rather than in a number of different sites. For this reason, the following hypothesis was developed.

H7: IS project team members are less likely to be dispersed geographically in small organizations than in large organizations.

Physical location may impact how a project team interacts. Communication, for instance, is easier when team members work in a single location. As concerns arise, project team members can easily move among offices to solve problems if they are located in a single location. The geographic proximity of team members may lead to regular communication reducing the need for formal project management tools such as the WBS and the Gantt chart. It seems logical that the following hypothesis can be developed.

H8: IS project teams in small organizations are less likely to use standardized tools and procedures such as the WBS, network analysis, Gantt charts, and Earned Value Reports than teams in large organizations.

\section{Methodology}

To test these hypotheses, a survey was developed to collect information from project managers. The targeted participants for this study were members of the Project Management Institute (PMI) professional organization. The survey questions were designed to collect information regarding respondent demographics, project performance and project management tools and practices used in their most recently completed project. The appendix provides a list of the survey items developed for this study.

To test the instruments validity, the survey was pilot-tested by six project managers in three different organizations. Feedback from the test team revealed that some questions were ambiguous and that the original response categories were too lengthy. It was suggested that to get individuals to complete the survey, it should be extremely concise, and unambiguous. The test group's feedback was integrated into the final survey. To test the reliability of the instrument, it was administered to 20 different experienced project managers and Ph.D. students.

The survey was available to the project managers for a period of six weeks. To address the potential threat of non-response bias in our sample, we performed a test of early and late responders. Early responders included the group of individuals $(n=53)$ who completed the survey in the first week and the late responders were the individuals who completed the survey in the last week $(n=37)$. The test showed that there were no significant differences $(\mathrm{alpha}=0.05)$ along key characteristics such as demographics, type of organization, project dimensions, performance measures, or geographic area. 
Most of the 128 respondents carried the title project manager ( 73 percent), were male ( 74 percent), and between the ages of 30 and 59 (95 percent). In terms of education, 84 percent held either a bachelors or masters degree and 59 percent had earned the project management certification. Respondents from private sector organizations accounted for 49 percent of the sample while 51 percent reported being part of a public sector governmental institution. Of the total, $46 \%$ reported working in large organizations and 54\% in small. Respondents were project managers from a broad range of IS project types across a variety of industries and from small and large, public and private sector organizations. The extensive representation of projects and organizations reduces concern of bias in the sample.

\section{Results}

Previous research infers that differences in organizational settings, namely sector and size, may impact various aspects of IS project management including the practices and tools used by the organization. To test differences between private and public sector organizations and between small and large organizations, a series of chi-square tests were performed. The chi-square test is a non-parametric test used to evaluate statistical significance for bivariate tabular analysis. The hypothesis tested with chi square is whether or not two different samples (for instance private versus public or small versus large) are different enough in some characteristic that we can generalize from our samples that the populations from which our samples are drawn are also different in terms of the characteristic. If the two variables are associated, chi-square tests will be significant and it can be concluded that there is a relationship between the two variables under study.

Before performing the chi-square tests, assumptions for the test were determined to have been met. First, the sample was randomly drawn from the population of PMI members, the population we wish to generalize our findings to. Second, response categories were judged to be mutually exclusive and exhaustive. Finally, the large sample size insured that the number of observed frequencies was adequate. Table 1 provides a summary of the chi-square tests performed to test the differences between private and public sector organizations.

Table 1: Chi-square Tests for Determining if Differences Exist Private versus Public Sector Organizations

\begin{tabular}{|l|c|c|c|}
\hline Variables & $\chi^{2}$ & $\mathrm{df}$ & $\mathrm{p}$ \\
\hline Project delivered within budget (yes/no) & 0.361 & 1 & 0.548 \\
\hline Project delivered on-time (yes/no) & 5.375 & 1 & 0.020 \\
\hline $\begin{array}{l}\text { Project team members more likely to be geo- } \\
\text { graphically dispersed (yes/no) }\end{array}$ & 0.165 & 1 & 0.684 \\
\hline WBS was effective (yes/no) & 0.032 & 1 & 0.858 \\
\hline Network Analysis was effective (yes/no) & 1.487 & 1 & 0.223 \\
\hline Gantt chart use was effective (yes/no) & 2.044 & 1 & 0.153 \\
\hline EVR was effective (yes/no) & 0.218 & 1 & 0.640 \\
\hline
\end{tabular}

The chi-square test showed that there was no association between sector of the organization and whether the project was delivered within budget. Of the public sector organizations, 43 percent did not meet financial budgets while 48 percent of the private sector organizations did not. Therefore, there is no evidence to suggest that public sector organizations are more likely to go over budget than private sector organizations. Hypothesis 1 was therefore rejected. 
A chi-square test showed that there was an association between sector of the organization and whether the project was delivered on-schedule. Private sector organizations delivered projects onschedule 63 percent of the time while public sector organizations were on-schedule only 42 percent of the time. From the statistical test, it can be concluded that there were significant differences between the two groups (public and private), providing support for hypothesis 2 .

In both public and private sector organizations, project teams were more often dispersed among two or more different locations. In private sector organizations, 74 percent of the teams were dispersed with 55 percent of all teams being located in 2-3 different areas, 11 percent in 4-5 different areas, and 8 percent in 6 or more different locations. In public sector organizations, 77 percent of the teams were dispersed with 37 percent of all teams being located in 2-3 different areas, 20 percent in 4-5 different areas, and 20 percent in 6 or more different locations. The chi-square test showed that there were not significant differences between the public and private sector organizations and thus there was no support for hypothesis 3.

To test which tools project teams were using, respondents were asked to report whether they found the work breakdown structure (WBS), network analysis, Gantt chart, and earned value reporting (EVM) to be effective tools. If a respondent did not report using the tool, it was assumed to be ineffective. Results show that the majority of teams in both public and private sector organizations found the WBS and Gantt chart tools to be effective. A total of 80 percent of the public sector organizations and 79 percent of the private sector organizations found the WBS to be effective. In addition, 70 percent of the publics and 81 percent of the privates found the use of the Gantt chart to be effective. However, only 21 percent of the publics and 31 percent of the privates reported network analysis to be effective while 23 percent of the publics and 19 percent of the privates reported EVR to be effective. Since, chi-square tests did not show significant differences between private and public sector organizations, hypothesis 4 was not supported.

Testing for differences between small and large organizations was similar to the set of tests completed on the public and private sector organizations. A series of chi-square tests were completed to determine whether there were significant associations between the groups on a number of different variables. Table 2 provides a summary of the findings.

Table 2:Chi-square Tests for Determining if Differences Exist Large versus Small Organizations

\begin{tabular}{|l|c|c|c|}
\hline Variables & $\chi^{2}$ & Df & $\mathrm{p}$ \\
\hline Project delivered within budget (yes/no) & 1.048 & 1 & 0.306 \\
\hline Project delivered on-time (yes/no) & 1.939 & 1 & 0.164 \\
\hline $\begin{array}{l}\text { Project team members more likely to be geo- } \\
\text { graphically dispersed (yes/no) }\end{array}$ & 0.087 & 1 & 0.769 \\
\hline WBS was effective (yes/no) & 0.501 & 1 & 0.479 \\
\hline Network Analysis was effective (yes/no) & 0.012 & 1 & 0.912 \\
\hline Gantt chart use was effective (yes/no) & 0.512 & 1 & 0.474 \\
\hline EVR was effective (yes/no) & 0.003 & 1 & 0.954 \\
\hline
\end{tabular}

Statistically, projects in small organizations were no more likely to be delivered late than projects in large organizations. In other words, there was no evidence to support hypothesis 5 . In small organizations projects were delivered late 58 percent of the time while 42 percent of them were 
reported to be delivered on time. In large organizations, 46 percent were delivered late and 54 percent on time. Results show that many projects are delivered late.

No evidence was found for hypothesis 6 either, as projects in small organizations were no more likely to be over budget than projects in large organizations. In small organizations projects were delivered over budget 58 percent of the time while 42 percent were delivered within the budget. In large organizations, 51 percent were delivered over budget and 49percent within budget. Overall, more than half of all projects went over budget.

Multiple-location teams were common with 79 percent of teams in small organizations being located in 2 or more places and 72 percent of teams in large organizations. While there were no statistical differences between small and large organizations and therefore there is no evidence to support hypothesis 7 , it is interesting to note that the majority of project teams were geographically distributed.

In terms of project management tools, the majority of teams in both small and large organizations found the WBS and Gantt chart tools to be effective. A total of 82 percent of the small organizations and 77 percent of the large organizations found the WBS to be effective. In addition, 78 percent of the small organizations and 72 percent of the large organizations found the use of the Gantt chart to be effective. However, only 25 percent of the small and 26 percent of the large organizations reported network analysis to be effective, while 21 percent of both the small and large organizations reported EVR to be effective. Since, chi-square tests did not show significant differences between small and large organizations, hypothesis 8 was not supported.

\section{Discussion}

The goal of this study was to explore differences in project management practices among organizations of varying size and in different sectors. Interestingly, there was little evidence that projects in private and public sector organizations and in large and small organizations are handled differently or have different outcomes. While project teams in public organizations deliver projects later than teams in private organizations, roughly the same proportion are over budget. Project teams in small and large organizations deliver the same proportion of projects over schedule and over budget.

The percentage of projects that were delivered over schedule and over budget in this study was largely comparable with values reported in previous studies. The Standish group (2001) found that 63 percent of projects were delivered behind schedule and 45 percent went over budget. One difference in the current study was that respondents from private sector organizations reported a higher level of projects being delivered on time - 63 percent compared with the 37 percent reported in the CHAOS study (Standish Group, 2001). This may suggest that improvements in project management are being made in private sector organizations.

In terms of project management tools, a majority of project teams, in private and public sector and in small and large organizations, reported using WBS and Gantt charts but only about a fourth of the respondents reported using EVM or a network analysis tool such as PERT. The use of EVM would seem to be important given that a high percentage of projects go over budget. Variances between budgeted and actual resource usage should be identified throughout the project life cycle.

Further review of the data showed that of the skill set (project management practices) identified by the Northwest Center for Emerging Technology Report (1999), only five were reported to be effective by 80 percent or more of the respondents. Table 3 provides a summary of the responses.

Defining the project scope, identifying and tracking critical milestones, reporting project status, identifying stakeholders and escalation procedures, and identifying required resources and budg- 
ets were reported most often to be effective practices. Least effective were preparing contingency plans and developing an initial project management flowchart.

Table 3: Summary of Respondents identifying Project Management Practices as Effective

\begin{tabular}{|l|c|}
\hline Project Management Practices & $\begin{array}{c}\text { Percentage of respondents who } \\
\text { found the practice to be effective }\end{array}$ \\
\hline Define the scope of the project & 88 \\
\hline Identify and track critical milestones & 87 \\
\hline Report project status & 85 \\
\hline Identify stakeholders, decision makers, and escalation procedures & 82 \\
\hline Identify required resources and budget & 79 \\
\hline Develop detailed task list (Work Breakdown Structure) & 78 \\
\hline Identify interdependencies & 72 \\
\hline Manage the change control process & 69 \\
\hline Participate in project phase review & 68 \\
\hline Estimate time requirements & 66 \\
\hline Secure needed resources & 49 \\
\hline Prepare contingency plans & 46 \\
\hline Develop and initial project management flowchart & 80 \\
\hline
\end{tabular}

This study shows that many of the practices and tools recommended by the project management profession were not utilized on projects or were reported to be ineffective. Thirty-five percent of the respondents did not develop a project management flowchart and 19 percent found the tool to be ineffective. In addition, 17 percent did not prepare contingency plans (32 percent found the tool to be ineffective) and 12 percent did not participate in project phase reviews (57 percent found it ineffective). Previous studies (Deephouse et al., 1995; Guinan et al., 1998; Yetton et al., 2000) have found that these practices improve project success. Perhaps this explains why many projects are delivered over-budget and behind schedule.

Organizations must recognize the importance of establishing sound project management practices when it comes to developing and/or implementing IS projects. As indicated earlier in this paper, IS projects are getting increasingly complex with many involving the internet, multiple service providers, and e-commerce applications integrating diverse cross-platform technologies. The findings of this research suggest that many of the practices and tools that have been suggested by researchers and organizations such as the Project Management Institute have not been successfully implemented in public and/or private organizations. If these organizations want to compete in the $21^{\text {st }}$ century, they will have to assess their project management practices against frameworks such as the Project Management Maturity Model (Sukhoo et al., 2005b); utilize software agent technology to support software development and project completion (Nienaber \& Barnard, 2005); and provide additional training in both hard and soft skills in project management practices (Sukhoo, Barnard, Eloff, \& Van der Poll, 2005a). It is only through assessment of an organization's current practices, providing ongoing training in project management practices, and implementing the necessary controls that ensure compliance with these establish practices that organizations can ensure they will be able to deliver IS projects on-time, on-budget, and provid- 
Furumo, Pearson, \& Martin

ing the desired functionality (Terry \& Standing, 2005). These functions can be provided by an ad hoc committee or through the development of a Project Management Office (PMO).

\section{Limitations of the Study}

Though this study provides interesting insights, it is important to acknowledge its limitations. The population surveyed consisted primarily of project managers. These project managers may be more skilled or at least more familiar with standardized project management practices than nonmembers. Even though only 58 percent of the respondents were actually certified in project management, generalizability of these findings may be limited to the population of project managers. Future research might address these limitations through broader population selection.

\section{Conclusions}

This initial study of IS project management in organizations of varying size and sector has shown that tools and practices used in project management are largely the same regardless of whether the organization is large, small, public, or private. The projects reported in this study experienced similar levels of budget overruns. However, projects carried out in public sector organizations were more likely to be delivered late. This is probably due to the increased oversight and numerous constituencies involved in these projects. Managers in these organizations need to be aware of the difficulties project managers face in these environments and strive to provide resources to overcome the obstacles of working in the public sector. At the very least, time contingencies should be built into these projects.

The results of this study are important to academicians in that they clearly suggest that future research should differentiate between private/public sector organizations when studying project management topics. This has not typically been done in previous studies in this area and may have caused some inappropriate conclusions and recommendations. Other issues that should be considered include ascertaining what measures of project success are currently in use and how valid these measures are; the effectiveness of the various project management methodologies, practices, and tools as related to achieving project success; and finally, which factors within the organization and outside the organization impact project performance.

\section{Acknowledgements}

Partial funding for this research was provided by the Pontikes Center for Management of Information.

\section{References}

Abdel-Hamid, T. (1999). The impact of goals on software project management: An experimental investigation. MIS Quarterly, 23, 531-555.

Aladwani, A. (2002). An integrated performance model of information systems projects. Journal of Management Information Systems, 19, 185-210.

Barki, H. \& Hartwick, J. (2001). Interpersonal conflict and its management in information system development. MIS Quarterly, 25, 195-228.

Beath, C. (1987). Managing the user relationship in information systems development projects: A transaction governance approach. Pittsburgh, PA: International Conference on Information Systems.

Billi, S. \& Raymond, L. (1993). Threats and opportunities for small and medium-sized enterprises. International Journal of Information Management, 13, 439-448.

Birkhead, M., Sutherland, M., \& Maxwell, T. (2000). Core competencies required of project managers. South African Journal of Business Management, 31, 99-105. 
Bretschneider, S. (1990). Management information systems in public and private organizations: An empirical test. Public Administration Review, September/October, 536-545.

Brooks, F. (1987). No silver bullet: Essence and accidents of software engineering. IEEE Computer, 20, $10-19$.

Caldeira, M. \& Ward, J. (2002). Understanding the successful adoption and Use of IS/IT in SMEs: An explanation from Portuguese manufacturing industries. Information Systems Journal, 12, 121-152.

Cats-Baril, W. \& Thompson, R. (1995). Managing information technology in the public sector. Public Administration Review, 55, 559-566.

Caudle, S. (1990). Managing information resources in state government. Public Administration Review, September/October, 515-524.

Collins, R. \& Kirsch, L. (1999). Crossing boundaries: The deployment of global IT solutions. Cincinnati, OH: Pinnaflex Educational Resources.

Deephouse, C., Mukhopadhyay, T., Goldenson, D., \& Kellner, M. (1995). Software processes and project performance. Journal of Management Information Systems, 12, 187-205.

Foster, M. (2001). Management skills for project leaders: What to do when you do not know what to do. Basil, Switzerland: Birkhauser.

Frame, J. (1994). The new project management: Corporate reengineering and other business realities. San Francisco, CA: Jossey-Bass.

Frame, J. (2003). Managing projects in organizations: How to make the best use of time, techniques, and people. San Francisco, CA: Jossey-Bass.

Guinan, P., Cooprider, J., \& Faraj, S. (1998). Enabling software development team performance during requirements definition: A behavioral versus technical approach. Information Systems Research, 9, $101-125$.

Hartman, F. \& Ashrafi, R. (2002). Project management in the information systems and information technologies industries. Project Management Journal, September, 5-15.

Heldman, K. (2003). Project management jump start: Project management basics. San Francisco, CA: Sybex.

Keil, K. \& Robey, D. (1999).Turning around troubled software projects: An exploratory study of the deescalation of commitment to failing courses of action. Journal of Management Information Systems, $15,63-87$.

Kirsch, L. (1997). Portfolios of control modes and IS project management. Information Systems Research, 8, 215-239.

Knol, W. \& Stroeken, J. (2001). The diffusion and adoption of information technology in small- and medium-sized enterprises through IT scenarios. Technology Analysis and Strategic Management, 13, 227246.

Nienaber, R.C. \& Barnard, A. (2005). Software quality management supported by software agent technology. Issues in Informing Science and Information Technology, 2, 649-669.

Newcomer, K. \& Caudle, S. (1991). Evaluating public sector information systems: More than meets the eye. Public Administration Review, 51, 377-384.

Northwest Center for Emerging Technologies. (1999). Building a foundation for tomorrow: Skills standards for information technology (millennium edition). Belleview, WA: National Science Foundation.

Schwalbe, K. (2004). Information technology project management. Boston, MA: Course Technology.

Standish Group. (2001). Chaos: A recipe for success. The Standish Group International

Stroeken, J. (2001). The adoption of IT by SMEs: The Dutch case. Journal of Enterprising Culture, 9, 129152. 
Sukhoo, A., Barnard, A., Eloff, M.M., \& Van der Poll, J.A. (2005a). Accommodating soft skills in software project management. Issues in Informing Science and Information Technology, 2, 691-703.

Sukhoo, A., Barnard, A., Eloff, M.M., \& Van der Poll, J.A. (2005b). An assessment of software project management maturity in Mauritius. Issues in Informing Science and Information Technology, 2, 671690.

Taylor, J. (2004). Managing information technology projects. New York, NY: AMACON (American Management Association)

Terry, J. \& Standing, C. (2004). Do project manager's utilize potential customers in e-commerce developments? Issues in Informing Science and Information Technology, 1, 663-672.

Weatherbe, J., Vitalari, N., \& Millner, A. (1994). Key trends in systems development in Europe and North America. Journal of Global Information Management, 2, 5-20.

Yetton, P., Martin, A., Sharma, R., \& Johnston, K. (2000). A model of information systems development project performance. Information Systems, 10, 263-289.

Zmud, R. (1980). Management of large software development. MIS Quarterly, 2, 45-55.

\section{Appendix}

This on-line survey was made available to members of the Project Management Institute. Those who completed the survey were asked to report on their most recent IS project team experience.

\begin{tabular}{|l|l|l|}
\hline \multicolumn{2}{|l|}{ Question } & Response Categories \\
\hline General Information & Yes/No \\
\hline 1 & Were you the project leader for this project? & under 30, 30-39, 40-49, 50-59, over 60 \\
\hline 2 & What is your age? & Male, Female \\
\hline 3 & What is your gender? & $\begin{array}{l}\text { High School, Bachelor Degree, Master } \\
\text { Degree, Ph.D. Degree, Other }\end{array}$ \\
\hline 4 & What is the highest level of education you have completed? & Yes/No \\
\hline 5 & $\begin{array}{l}\text { Was the most recent project you worked on for a company of } \\
500 \text { or fewer employees? }\end{array}$ & $\begin{array}{l}\text { Public/Private } \\
\text { the public or private sector? }\end{array}$ \\
\hline 6 & $\begin{array}{l}\text { Was the most recent project you worked on for a company in } \\
\text { questions } 8 \text { and 9. }\end{array}$ & Yes/No \\
\hline 7 & Was the project early or late? & Early/Late \\
\hline 8 & How many months early or late was the project? & Actual number \\
\hline 9 & How many times was the project schedule modified? & Actual number \\
\hline 10 & $\begin{array}{l}\text { Was the project completed within budget? If no, answer ques- } \\
\text { tions 12 and 13. }\end{array}$ & Yes/No \\
\hline 11 & Was the project delivered over- or under-budget? & Overbudget/Underbudget \\
\hline 12 & What percentage over or under was the budget? & Actual percentage \\
\hline
\end{tabular}




\begin{tabular}{|l|l|l|}
\hline \multicolumn{4}{|l|}{ Geographic Distribution of Project Team Members } \\
\hline 14 & $\begin{array}{l}\text { Did team members work in the same location? If no, answer } \\
\text { questions 15 and 16. }\end{array}$ & Yes/No \\
\hline 15 & $\begin{array}{l}\text { In how many different geographic locations were team mem- } \\
\text { bers located? }\end{array}$ & $2-3,4-5,6$ or more \\
\hline 16 & Were some members located in different countries? & Yes/No \\
\hline Project Management Tools & Yes/No \\
\hline 17 & Did you find the use of a WBS effective? & Yes/No \\
\hline 18 & Did you find the use of a Network Analysis effective? & Yes/No \\
\hline 19 & Did you find use of a Gantt Chart effective? & Yes/No \\
\hline 20 & Did you find use of the EVR effective? &
\end{tabular}

\section{Biographies}

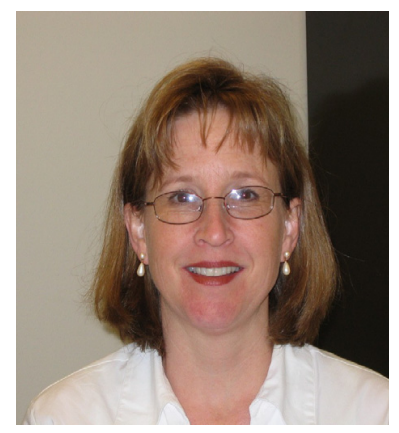

Kimberly Furumo is an Assistant Professor of MIS at the University of Hawaii at Hilo. Her research interests include IS project management, humancomputer interaction, and virtual teams and her work appears in the proceedings of the Hawaii International Conference on System Sciences, the Americas Conference on Information Systems, and the annual meeting of the Decision Sciences Institute. Prior to joining the faculty, Dr. Furumo worked in the business and IT areas. She has been a member of several IS project teams.

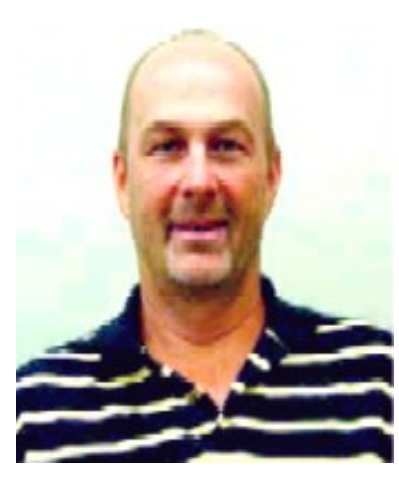

J. Michael Pearson is an Associate Professor of Information Systems at Southern Illinois University @ Carbondale. Dr. Pearson currently serves as editor for the Journal of Internet Commerce and as director of the Pontikes Center of Information Management. Dr. Pearson has presented several papers at regional, national and international conferences. He has published articles in Communications of the ACM, Information \& Management, Journal of Strategic Information Systems, Journal of Information Systems, Journal of Computer Information Systems, Decision Support Systems, Review of Business, Journal of Internet Commerce, Information Resources Management Journal and Public Administration Quarterly. His research interests are in the areas of technology adoption, e-commerce, management of quality, and IT project management.

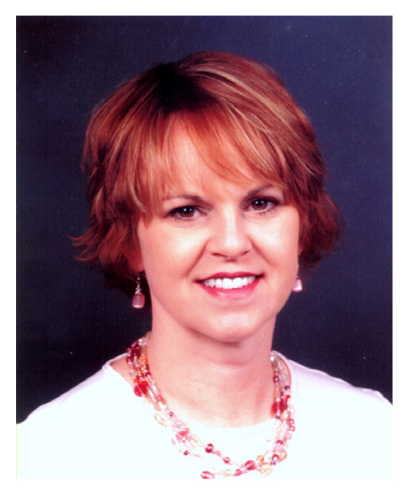

Nancy L. Martin is a Doctoral Candidate in Information Systems at Southern Illinois University in Carbondale. Her research interests include IS strategy, IS project management and human-computer interaction. Her work has been published in the International Journal of Web Based Communities as well as in the proceedings of the Hawaii International Conference on System Sciences, the Americas Conference on Information Systems, and the annual meeting of the Decision Sciences Institute. Her dissertation research, which focuses on the value of business method patents, was accepted into the Doctoral Consortium of the 2005 International Conference on Information Systems. 